Trinity University

Digital Commons @ Trinity

School of Business Faculty Research

School of Business

$7-2022$

\title{
Female Sports Officials and Mental Health: The Overlooked Problem
}

Jacob K. Tingle

Trinity University, jtingle@trinity.edu

B. L. Jacobs

Lynn L. Ridinger

Stacy Warner

Follow this and additional works at: https://digitalcommons.trinity.edu/busadmin_faculty

Part of the Business Administration, Management, and Operations Commons

\section{Repository Citation}

Tingle, J. K., Jacobs, B. L., Ridinger, L. L., \& Warner, S. (2022). Female sports officials and mental health: The overlooked problem. Journal of Sport Management, 36(4), 383-393. https://doi.org/10.1123/ jsm.2020-0443

This Post-Print is brought to you for free and open access by the School of Business at Digital Commons @ Trinity. It has been accepted for inclusion in School of Business Faculty Research by an authorized administrator of Digital Commons@ Trinity. For more information, please contact jcostanz@trinity.edu. 
Female Sports Officials and Mental Health: The Overlooked Problem

Submitted on July 23, 2021 


\begin{abstract}
Sporting culture often celebrates mental toughness and chides weakness, which can stigmatize mental health issues. While some sport organizations have prioritized addressing mental wellbeing, referees have been ignored. Referees work in high-pressure environments thus the need to understand, destigmatize, and normalize the conversation around mental health within the referee community and the larger sporting system is important. Because the prevalence of stress-related issues is greater for women, this study focused on female referees' well-being, interviewing 20 female U.S. basketball referees via a hermeneutic phenomenological approach. Participants represented various geographical regions in the United States and officiated at levels ranging from high school to professional. Findings revealed Gendered Aggressions negatively impacted the referees, mental health issues are Stigmatized, and more Resources and Support are needed. Results also indicated that officiating can be Cathartic. Suggestions for addressing the referee shortage and improving the officiating experience are included.
\end{abstract}

Keywords: Referees, Retention, Stigma, Women's Sports 


\section{Female Sports Officials and Mental Health: The Overlooked Problem}

Those familiar with competitive sports at all levels know that the media (Borel-Hänni, 2015; File, 2017; Webb, 2018), fans, players, coaches (Jacobs et al., 2020; Ridinger, Warner, et al., 2017; Ruddock-Hudson et al., 2019), and indeed sport leagues themselves (Tingle, 2020) often demand perfection from referees. And, previous researchers have found that the immense pressures faced by sports officials, even those at the grassroots and community levels (Ridinger, 2015), could lead to many psychological stressors (Taylor et al., 1990; Webb \& Hill, 2020). Such stressors, along with the abuse from multiple stakeholder groups (Folkesson et al., 2002; Jacobs et al., 2020), have created sustained issues with both recruitment and the retention of referees from the grassroots through elite levels (Cuskelly \& Hoye, 2013; Ridinger, Kim, et al., 2017; Webb \& Hill, 2020). Many U.S. sport associations (Jordan et al., 2019; Ridinger, Kim, et al., 2017), and those across the world (Mellick, 2020; Webb et al., 2020) are experiencing referee shortages and retention challenges that endanger the future of sport (Dell et al., 2016; Eilerson, 2017; Livingston et al., 2017).

Working in a high-pressure environment, rife with abuse and demands of perfection, can lead to alarming outcomes. Many referees seek to hide or mask mental health concerns (Mellick, 2020 ) and $80 \%$ of new sports officials quit before their 3rd year on the job (Stump, 2018). One way to reduce this alarming attrition rate is to recognize and address the impact of mental health challenges associated with officiating. The mental health benefits of youth sports have been emphasized (U.S. Department of Health and Human Services, 2019), and sport leagues at the college (Carr \& Davidson, 2014), and professional levels (Pinto, 2019) recognize the need to create mental health programs. However, referees almost entirely have been left out of the conversation (Gulliver et al., 2012; Hanton et al., 2005; Rao \& Hong, 2016; Voight, 2009). As a 
result, referees are often left to seek mental health resources on their own (Mellick, 2020). Like other professions without adequate mental health resources (Lambert et al., 2004; Rao \& Chandraiah, 2011), officials may experience increased levels of anxiety (Dell et al., 2016) and anger (Webb et al., 2017). Further, without the direct support of professional associations and supervisors, referees will continue to drop out, and there will be missed opportunities to recruit and train new individuals to become referees (Kellett \& Warner, 2011; Ridinger, Kim, et al., 2017; Ridinger, Warner, et al., 2017; Tingle et al., 2014; Warner et al., 2013). There is a clear need to better retain and recruit referees, especially female referees (Nordstrom et al., 2016; Schaeperkoetter, 2017; Tingle et al., 2014).

Researchers have found that women leaders in the male-dominated sport culture may experience minority stress that results from prejudice and discrimination, disparate treatment, and internalizing negative stereotypes associated with their marginalized identities (Melton \& Bryant, 2017). Furthermore, there are gender differences in the prevalence of stress and mental health challenges, with women being more at risk (Cavanagh et al., 2015; Martín-Merino et al., 2010; Wolanin et al., 2017). Women within sport organizations with multiple marginalized identities (e.g., gender, race, sexual orientation) tend to be socially isolated and the mental and professional toll of being "othered" has motivated many women to pursue career opportunities in more inclusive, non-sport industries (Walker \& Melton, 2015). Given the shortage of referees and challenges faced by women in sport, the exploration of mental health among female referees becomes a necessary yet overlooked issue. Thus, the purpose of this study was to explore how female referees experience mental health in the context of sports officiating. A better understanding of this issue can inform strategies to enhance referee mental well-being and appropriate support can be provided. 


\section{Literature Review}

\section{Referee Stressors}

Officiating is a unique role whereby the official is responsible for managing the match, applying the rules, allowing for fair competition, and ensuring the safety of all participants (Dell et al., 2016). Due to the multi-faceted nature of this role, much of the historical literature regarding sport officials has focused on stress experienced within the role (Anshel \& Weinberg, 1995; Rainey \& Hardy, 1999; Voight, 2009). These numerous stressors include fear of failure (Johansen \& Haugen, 2013; Rainey, 1995), interpersonal (Anshel \& Weinberg, 1995) and role conflicts (Voight, 2009), travel demands (Warner et al., 2013), and work-life balance issues (Tingle et al., 2014). As stressors continued to be identified, the research evolved to explore coping mechanisms propagated amongst officials (Anshel \& Wells, 2000a, 2000b; Anshel et al., 2014; Kaissidis-Rodafinos et al., 1997) and considered how one might reframe negative occurrences in order to cope. Kellett and Shilbury (2007) found that referees were able to reframe abuses to manage stress, while Kellett and Warner's (2011) follow up work noted the importance of referee community in this re-framing process which helped retain officials.

Retaining referees continues to be of utmost importance as referee organizations worldwide experience referee shortages. Referees regularly discontinue participation for a number of reasons, including the aforementioned role stressors (Anshel \& Weinberg, 1995; 2008; Cuskelly \& Hoye, 2013; Rainey \& Hardy, 1999; Webb \& Hill, 2020). Recent research has considered ways to mitigate this alarming trend (Ridinger, Kim et al., 2017) while also better understanding why referees 'stay in the game' (e.g., Ridinger, Warner, et al., 2017). Such retention strategies have included creating community, enhancing administrator consideration, clarifying role expectations, and reducing or reframing the abuse/stresses (Kellett \& Warner, 
2011; Jacobs et al, 2019; Ridinger, Kim, et al., 2017; Ridinger, Warner, et al., 2017; Warner et al., 2013). While the reduction of stress is crucial, it is only a small part of referee mental health and wellness experience. Few studies have explored the impact of those stressors on mental health outcomes (Webb \& Hill, 2020) and only one study has specifically explored mental health and wellness among female sports officials (cf. Webb et al., 2021). This research builds upon foundational referee research and utilizes mental health frameworks to explore how female referees experience mental health so that sport managers can better address the referee shortage.

\section{Mental Health in Sport}

Mental health is "a state of well-being in which the individual realizes his or her own abilities, can cope with the normal stresses of life, can work productively and fruitfully, and is able to make a contribution to his or her community" (World Health Organization, 2004, p.10). This expands the definition of mental health beyond the mere absence of mental illness and begins to consider one's mental health on a continuum, departing from the mental health versus mental illness dyad (Schinke et al., 2017). Emerging definitions of mental health suggest a relationship with both physical and social well-being, and how each plays a role in health and effective functioning. The renewed focus on mental health has led to a growing body of research on athlete mental health, particularly elite athletes, as scholars seek to expand resources and support for sports participants (Hanton et al., 2005; Kubayi et al., 2018; Madrigal \& Robbins, 2020). And, despite organizations like the International Olympic Committee advocating that mental health of athletes and coaches should be a primary focus of researchers in coming years, officials have been categorically excluded from the narrative (Reardon et al., 2019).

To date there have been few studies exploring the mental health of sports officials - of either gender (Gouttebarge et al., 2017; Webb et al., in press). In a study on European 
professional football referees, Gouttebarge et al., (2017) found the incidence of symptoms of common mental disorders to be $10 \%$ for distress, $16 \%$ for anxiety/depression, $14 \%$ for sleep disturbance, $29 \%$ for eating disorders and $8 \%$ for adverse alcohol use. The referees in this study reported that the development of specific support tools for them are needed in order to properly manage these symptoms. Webb and colleagues (in press) interviewed 12 female soccer match officials and found that gendered abuse and masculine dominated sporting environments negatively impacted the mental health of participants during and after matches. Their findings further indicated the need for more mental health resources and a stronger educational program focused on coping techniques. Given the problems of recruitment and retention of referees, Webb (2020) suggested that the dearth of literature exploring the mental health of sport officials deserves immediate attention.

In addition to Webb's call for scholars to better understand referee's mental health, previous research has shown sport to be a unique context for understanding mental health, as sport participation has the potential to enhance self-perceptions (Lubans et al., 2016), allow for personal anxiety management (Woodward, 2004), protect against depressive symptoms (Boone \& Leadbeater, 2006) and provide opportunities for social connection (Jewett et al., 2014; Warner, 2019). Jewett and colleagues (2014) also found that those who had participated in sport had more favorable scores on three mental health indicators than did their non-sporting peers, while Warner (2019) advocated sport as medicine for achieving holistic health. These studies make the case that sport participation can lead to positive mental health outcomes and that officials might also see such benefit.

Phillips and Fairley (2014) suggested that the referee experience was similar to that of athletes. The physical requirements for referees are similar to athletes and therefore the same 
testing methods have been used as for measuring athlete and referee performance (Coutts \& Raeburn, 2000; Leicht, 2008). Furthermore, career progression and appropriate development of skills is similar to athletes' experiences. That is, novice referees begin by working lower-level before progressing to higher levels of competition. Phillips and Fairley (2014) found that umpires viewed themselves as athletes and that umpiring had central importance in their lives; umpiring was perceived as a very positive, active, and healthy component of their lifestyles. The researchers also noted that the social camaraderie and sense of community developed among umpires was an important source of support that enabled them to deal with fan abuse.

It should be noted that the impact of sport participation on mental health can be dichotomous. While there can be positive benefits, elite participants may experience stressors and challenges that are unique to the sporting context (Rice et al., 2016). Previous research indicated that the sporting culture may also hinder an athlete's help seeking behavior for fear of being considered weak by teammates or coaches (Bauman, 2016; Gulliver et al., 2012; Lopez \& Levy, 2013), due to the potential for reduced playing time (Putukian, 2016), or as a result of denial of and stigmatization of mental health by others (Hughes \& Leavey, 2012; Kaier et al., 2015; Van Raalte et al., 1992). Sport participants are under immense pressure and are expected to be mentally tough, including fighting through both physical or mental pain (Schinke et al., 2018). However, athletes tend to identify issues as problematic only when their performance is influenced (Gerbing \& Thiel, 2016), meaning that mental health is interpreted based upon performance abilities rather than medical diagnostic criteria (Coyle et al., 2017). The stigma associated with mental health issues and help seeking behavior also provides another obstacle in the sporting context. Stigma impedes help seeking for athletes (Coyle et al., 2017) and likely leads to underreported, under-diagnosed and/or under-treated mental health issues (Schwenk, 
2000). These insights gleaned from athletes may play a key role in understanding referees' mental health.

\section{Gendered Conceptualizations of Mental Health \& Sport}

Within the sport officiating context, the unique experiences of female referees are often overlooked. In fact, according to Hancock and colleagues (2020) of 386 publications on officials in the last 50 years, "only five studies $(1.3 \%)$ revolved around understanding the experiences of female sport officials" (p. 6). Not only are female sport officials underrepresented in existing research, but the intersection of their gender and athletic identities leads to mental health experiences that may be dramatically different than male counterparts. For example, women are nearly twice as likely to be diagnosed with an anxiety disorder (Martín-Merino et al., 2010) and depressive symptoms have been shown to be moderated by gender (Cavanagh et al., 2015). These notions are further corroborated by two studies comparing male and female athletes: one which found U.S. female college athletes reported a higher rate of depressive symptoms (Yang et al., 2007) while another found female athletes have exhibited 1.84 times the risk of developing clinical mental health symptoms (Wolanin et al., 2016). Although women are statistically more likely to report certain mental health symptoms, they also exist in a world where the expectations, particularly of female sport participants, are significantly influenced by misogynistic sporting cultures and antiquated expectations of the female's presentation and role (Hindman \& Walker, 2020).

Traditional gender roles have been shown to impact how athletes are treated or in many cases, mistreated both on and off the field (Breger et al., 2019; Guzel, 2020; Krane, 2015). Thus, beyond the traditional stressors, female referees must also contend with additional gendered stressors including: Lack of Mutual Respect, Perceived Inequity of Policies, Lack of Role 
Modeling and Mentoring, and Gendered Abuse (Tingle et al., 2014). These gendered stressors were further corroborated by Schaeperkoetter (2017) who found that her 'femaleness' impacted the way she was perceived as an official. And, in a study of world karate referees, Guzel (2020) found the lack of role models and a male dominated work environment were stressors only experienced by female referees.

Much like gender has shaped the understanding and experience of officiating in these previous studies, gender also shapes the understanding and experience of mental health (Coyle et al., 2017). This gendered arena creates a unique context in which to explore mental health within the officiating population. As a central figure in a sporting contest, and with extant literature pointing to officiating as a stressful role within a gendered sporting context, it is paramount to examine the experience and construction of mental health among female sports officials. Thus, this research is guided by the following question:

How do female referees experience mental health in the context of sports officiating?

\section{Method}

In an effort to better understand mental health as experienced and understood by female referees, a hermeneutic phenomenological (Laverty, 2003) approach was taken. Such an approach allowed for the exploration of common lived human experience within a specific social setting, in this case sports officiating, (e.g., Kellett \& Warner, 2011; Nordstrom et al., 2016; Tingle et al., 2014). The interpretive element of hermeneutic phenomenology understands that one cannot bracket out external influences entirely, rather their interpretation of the experience is part of their understanding (Huang et al., 2006). Guided by this phenomenological approach, semi-structured interviews allowed participants to articulate issues and experiences they saw as fit, enabled the interviewer to further explore interesting and profitable points, and ensured data 
collected were comparable between interviews. Moustakas (1994) suggested the inclusion of two broad questions within each phenomenological study: (a) what have you experienced in terms of the phenomenon; and (b) what contexts or situations have typically influenced or affected your experiences with the phenomenon? Such overarching inquiries guided the development of the interview guide. The interview guide was then field tested with four basketball officials averaging 19 years of experience to ensure that participants were being asked relevant questions in an appropriate way (Pyett, 2003). Such field testing allowed for validation of the interview guide and minor adjustments were made to ensure clarity and pacing of the interview questions. None of these experts participated in the subsequent study.

Questions included: “What is your current knowledge of the term mental health (MH)?”, "How do you maintain your mental health?", "What in your sport causes you to be happy/sources of happiness?", "What stigma/barriers are you aware of relating to MH in (your) sport?, and "Can you tell me about any experiences you have had with MH related issues as an official?"

\section{Procedures and Research Participants}

After receiving Institutional Review Board approval, 20 female basketball referees in the U.S were recruited via their respective officiating organizations. We acknowledge the difference between a sex label (female) and a gender label (woman/women); the participants in this study used the terms interchangeably, as is often the case when discussing issues related to gendered ideology. Researchers sought to recruit participants with a diversity of experience levels (i.e., referees who worked at the: NCAA Division I college level or higher, NCAA Division II or III level, and high school varsity level). Referee organizations in the U.S. Census Bureau's four geographic regions were contacted using personal networks and cold-outreach. Female 
basketball referees were specifically targeted because of the relatively large number of females who officiate basketball. All participants were given pseudonyms to maintain confidentiality. In some instances, the participants may have been the only official in a particular set of demographic categories, thus demographic information which could be identifying has been withheld.

\section{[Insert Table 1 here]}

After obtaining written consent, interviews ranging from 38 to 109 minutes were conducted via phone with 20 female basketball officials. Interviews were conducted until data saturation was reached (Guest et al., 2006). "By definition, saturated data ensure replication in categories, which in turn verifies and ensures comprehension and completeness" (Elo et al., 2014, p. 5). The average interview lasted 72 minutes and all interviews were audio recorded and professionally transcribed to increase trustworthiness and transferability of the data and its subsequent analysis. The data analysis was performed by all four researchers, increasing the ability to provide a thorough interpretation of the data. (Burla et al., 2008; Schreier, 2012). And, throughout the analysis process the researchers continually reflected on their processes which helped ensure that interpretations were firmly grounded in the data (Thomas \& Magilyy, 2011) and reflected the participant's voice and experience (Lincoln \& Guba, 1985).

In hermeneutic phenomenology it is understood that, much like a participant, the researcher cannot completely bracket their own lived experiences, but instead must acknowledge their own lens (Huang et al., 2006). Researcher positionality allows scholars to "provide more thoughtful and critical representation of ourselves within our research" (Misener \& Doherty, 2009, p. 466). Three of the authors have on-field officiating experience. Author one officiated basketball for 20 years, including 18 years of collegiate officiating, and 10 years at the NCAA 
Division-I level. Author two was a field hockey official for six years at the U-19 and U-16 club levels and the Referee Manager for a National Governing Body for four years. Author three officiated field hockey and lacrosse for 18 years, primarily at the high school and Division III college levels. And, Author four is a former college athlete that has conducted numerous indepth studies on sport officials over the past decade but has not held any formal sport officiating role.Their sports officiating experiences have helped the authors gain practical insight into the role of referees. As delineated by Corbin and Strauss (2008): "when we share a common culture with our research participants ... it makes sense, then, to draw upon those experiences to obtain insight into what our participants are describing" (p. 80).

From this frame of reference, inductive thematic analysis (Braun \& Clarke, 2006) was utilized as each of the four researchers independently coded five different transcripts and an initial set of codes emerged from the data. Three of the four researchers had officiating experience, which ensured a balance of both an insider and outsider perspectives throughout the coding process (Willig, 2007). Allen-Collinson (2009) noted that having the insider and outsider perspective allowed the research team to avoid "imposing their own meanings and constructs upon the accounts of the 'expert' participants" (p. 209). After coding the 20 transcripts, an iterative process was utilized to condense the most salient first level codes into emergent themes that best represented the participants' understandings of mental health in the officiating context.

The saliency of the codes was determined by the usage frequency of the participants. The emergent themes were then shared with an external reviewer to debrief the findings (Onwuegbuzie \& Leech, 2007). Such a process allows the researchers' assertions to be challenged (Lincoln \& Guba, 1985) and helps "assess whether the findings are plausible, based on the data" (Merriam \& Tisdell, 2016, p. 250). The authenticity of the results is highlighted by 
the emergent themes which detail the officiating experience as multi-dimensional (Lincoln \& Guba, 1985; Polit \& Beck, 2012) and is further showcased through the use of direct participant quotes.

\section{Results}

After analyzing the data, four themes emerged regarding how female referees experience mental health. Themes included: 1) Gendered Aggressions against female referees, 2) Stigma associated with mental health issues, 3) Resources and Support available for referees to help manage mental health challenges, and 4) officiating as a Catharsis to relieve stress. The themes are presented in order of saliency with representative quotes that best reflect the participants overall insights.

\section{Gendered Aggressions}

Eighteen of the 20 referees who participated in this study indicated they had experienced gender related macro and microaggressions which negatively impacted their mental health. The gendered aggressions described by study participants were often described as insidious. That is, the actor often did not overtly intend to cause harm. Nonetheless, the impact was felt. Edith explained:

So, self-esteem, anxiety, stress, fear. Those four are huge for most officials. And especially females . . . because someone berating you or making you feel less than other folks ... even your [officiating] partner is making you feel that way. That can affect your self-esteem, so then you start really believing that you're not good. And not just in basketball. You start applying it to everything in your life, because you see it as a failure. Participants detailed the emotional strain of being denied opportunities, being sexually objectified, or being questioned about their abilities because of their gender. In some cases, a 
single experience caused increased stress and anxiety and in others, the cumulative effects led to negative mental health outcomes. For example, in many instances the participants noted that they had been denied opportunity to officiate boy's or men's games because of their gender. Angela explained, "when I got here I was told that male coaches probably aren't going to be comfortable with me officiating their games." Being denied such opportunities heightened anxiety and feelings of self-doubt for the female referees.

Further, 12 of the 20 female participants specifically mentioned the stress that existed because the existing officiating structure often operated like an 'old boys' network' or a boys' club. That is, leadership roles in many officiating organizations are held by men, assignment decisions are made primarily by men, and at association meetings the environment preserved is that of a locker room, which Jacinta described as meaning that crude humor and overt sexism are accepted or promoted. Eighteen participants further indicated that being questioned simply because they were a woman in a male dominated environment negatively impacted their mental health. They noted that they were often undermined, sharing examples including male referees making calls on their behalf. Such issues are exacerbated when coaches would proceed to ignore the female referee. Jacinta explained that instead of speaking to her when she made a call that the coach disagreed with; the coach would speak to one of her male counterparts instead. "That really bothers me because it's almost like, 'I don't even respect you enough to talk to you about the calls that you're making. I only want to discuss the game with your male counterpart."”

Along with being bothered or concerned with the "sexism and this discrimination in officiating" (Lucinda), participants recounted instances where they had been sexually objectified in the role. Gabriella explained, "they won't say anything to a guy who may have like a belly, but let me have some hips. Yeah, they're going to say something ... So, there's always been a double 
standard." Women referees also experienced stress related to the expected to present a 'feminine' appearance. Dameka clarified, "I think it's a very narrow kind of image of what a woman should [be] like. What a female official should look like." She further described how these gendered body standards negatively impacted her mental health: "This is where officiating for me is the hardest ... is that I can start to feel really negative about my body because I feel like every night when I step out there, people are judging how I look.” Bella described a stress inducing conversation with a male assignor who indicated that her credibility would be diminished if she was not better than male officials: "They're going to all say that you got where you got because [you're] cute, that you look like a Barbie doll." Experiencing gendered aggressions related to the female aesthetic, along with "sexist remarks about how I'm acting or it's not my place out there" (Lucinda) were regularly recounted. In more extreme instances others described their personal space being invaded. For example, Rena stated, "I had a coach, he came up and kind of put his arm around me. But it wasn't like the same way he would put his arm around a guy," significantly and detrimentally impacted the female referees' mental health in this study.

Despite their position of power on the court, the participants noted that they had experienced countless gendered aggressions during their careers. Such occurrences significantly and detrimentally impacted the female referees' mental health in this study. Angela summed it up, "There's a lot of sexism that comes into play still, which is unfortunate." Sarah explained, "Whatever that it is, it just feels like it affects women more than it does men." The accumulation of gendered aggressions was described overall as leading to mental health challenges for the study participants.

\section{Stigma}


Of the 20 referees interviewed for this study, 18 alluded to a Stigma attached to mental health issues. When asked about personal perceptions of mental health, most of the referees in this study indicated there is a stigma associated with the term "mental health," and for some, mental health was equated with mental illness. Dolores said, "It [mental health] has a really bad stigma, so it keeps people from getting the help that they need to just deal with it. Nobody wants to be deemed crazy." She continued, "nobody wants to be called that, so you don't want to go out of your way to talk about your mental health because of that." Other referees revealed personal struggles with mental health and how those impacted their perceptions of the term.

Fifteen referees specifically noted that mental health issues are rarely discussed in society in general and are wholly ignored within the context of their officiating worlds because of the stigma associated with the term. Angela stated, "I think overall as a country we don't talk about it and in sports, athletes are supposed to be heroes. So, there's definitely stigma in mental health in sport, but I think there's also stigma in mental health overall." Hope also noted, "Yeah, we don't really talk about it very much in sports. I think that's a societal thing. There's not a lot of places that we do talk about mental health yet, and I think we should talk about it more often."

According to those 15 participants, mental health is not being addressed within officiating associations. Talking about mental health issues as officials is "still taboo" (Trina) and "most people won't say anything because it's not cool" (Kirsten). Alana, who has been officiating at the Division I level for over 20 years, stated, "I'm not sure that I've ever heard the word mental health in all of my years of officiating." According to her, there is no concern from administrators or assignors about mental wellness. Seven participants (Alana, Angela, Caitlin, Hope, Jacinta, Kathy, Lucinda) noted that administrators only care that referees were physically fit and prepared to work the game. Kathy also indicated that personal mental health issues are not 
addressed within her officiating association: "I just don't think it's been brought to the table yet in a way that it's creating a platform where people are talking about it."

The limiting factor in the discussion of mental health amongst referees is stigma and the associated fear of mental health issues being perceived as weakness. Edith detailed the impact of the stigma on her mental health: "I was just burying those things deep inside and not allowing them to come out because I didn't want my image to be tarnished." Angela noted, "So I definitely see some of the stigma associated with not talking about it [mental health] because then if you talk about it and you say that you have a problem, are you then removed from the game?" Dameka also indicated that the stigma would prevent her from reporting a problem, "I think it can be hard because of the competitive aspect among officials. That if you're not handling something very well, you're kind of admitting to a weakness." Caitlin detailed the difference between perceptions of physical and mental health: "I would be afraid to tell my supervisor, honestly. It's hard enough telling them, 'Yeah, I've got a knee injury,' But it would be really hard if I told them, 'Man, I'm having trouble with depression, or anxiety. . ." The referees in the study described how the Stigma associated with reporting mental health negatively impacted their own experiences.

\section{Resources and Support}

Given the results regarding the stigmatization of and the aversion to discussing mental health issues, it was not surprising to find there were limited resources and support for referees to manage mental health challenges. Seventeen of the 20 referees commented on the lack of Resources and Support regarding mental health issues within officiating organizations. Rena felt that the lack of mental health support within officiating communities contributes to attrition of officials. She stated, "I think that's probably the number one reason why we lose officials, just in 
general, because they don't have that support system around them." When asked about mental health resources for referees, Edith indicated that no attention was given to mental health issues for officials in her region.

I don't even think we recognize it. If . . somebody came to us and said, 'I'm experiencing this mental health issue,' I think we all would probably be in shock because we don't even pay attention to it, even though it's right there in front of us and it's so prevalent now, that we should. No, not even at the state level, not at our level . . not at all. Jacinta commented on increases of mental health support for athletes, but that sports officials are left out of the conversation. "There's a huge lack of discussion of mental health of officials. And I'm seeing an increase in discussions of mental health for athletes in recent years . . . but it has not reached the officiating world." Gabriella noted that her officiating association had a two-year mentorship program in place, but there were no resources provided to the mentor or mentee about mental health issues.

Seven referees suggested that mental health resources and support could be incorporated into camps, conferences, and association meetings. For example, Hope said: "They do teach us how to work with coaches and parents, but never like talking about mental health. Within those camps, and the conferences, would be a good place." Jacinta also highlighted current officiating continuing education sessions as a great place to introduce mental health resources: "It would be awesome to have kind of a clinic at these camps to talk about . . . how to overcome when you're feeling overwhelmed . . or just how to balance those things mentally and emotionally." She indicated that camps and clinics are not the only times when mental health literacy could be discussed. "At these meetings we're having, we should be having people come in a few times a season to talk about the mental and emotional aspects of what we're doing every day, at least on 
the court." The lack of specific mental health Resources and Support was a negative element of the basketball officiating experience for most referees in the study.

\section{Catharsis}

Another salient theme detailed by 17 of the 20 participants was the idea that officiating can be a Catharsis. While the officials discussed myriad stressors that may negatively impact their mental health, they also noted that officiating has the potential to provide a positive outlet. Angela recounted a time when she was injured and unable to officiate, “. . . what I did not realize is how much officiating helps me de-stress.” Hope explained, “. . [officiating] gives you an outlet for all your feelings. It gives you somewhere with no distraction, which helps you work out the feelings that you have sometimes." She continued, "I think also working with other people helps that. Makes you realize you're not necessarily alone." As officials focused on the game they could escape their external concerns and find connection to a sport that they hold dear. Such an opportunity is shown to allow for reflection and to help reduce the stress that may be experienced in external settings. Kathy described a conversation with her doctor,

She asked me how I can officiate basketball. And I said, 'Well, I'm in control. When I'm out there, it's the only thing I'm thinking about. So, I'm not worrying about my two kids. I'm not worrying about my husband. I'm not worrying about my job. I'm just thinking about basketball and nothing else.'

According to Angela, the intense focus required to officiate seemed to promote one's ability to 'zone out' external stressors. Some officials found that as they were liberated from their day-today concerns they found power and joy in their on-court responsibilities. "I'm not just a body on the court, I'm a contributor," recounted Selina. Janae expanded, describing the notion as invigoration, "I feel alive when I'm just on the court and a part of the game. I love the interaction 
that I have between my partners ... I just feel like I am involved in the . . sport that I loved.” And, Camelia explained the power she found in, “...just getting your mind in basketball mode and leaving everything else behind." In this way officiating provides potential for both Catharsis and may serve as a tool for both stress relief and maintaining mental health. Because officiating provides a physical and mental escape from the stresses of everyday life, most participants found that, given the right conditions, officiating can be a catharsis.

\section{Discussion}

Despite efforts to bring more awareness to mental health issues in many sport settings, officiating lags behind other sectors. By exploring how female referees experience mental health, the officials in this study described an officiating experience that was rife with Gendered Aggressions. In numerous instances officials' mental health was negatively impacted as they felt relegated to second class citizens when those in power refused to assign them to men's games and evaluated their abilities based on appearance rather than skill. This aligns with Krane (2015) who proposed that women are limited by hegemonic power grounded in perceptions of male sporting superiority, Hindman and Walker (2020) who found that expectations of female sport participants were negatively impacted by misogynistic sport cultures, and Melton and Bryant (2017) who found that women often internalize negative stereotypes associated with masculine dominated sporting cultures.

At both a macro and micro level, female officials were forced to contend with Gendered Aggressions. The compounding microaggressions they identified - being undermined, belittled, or objectified - had the potential to amplify the already numerous stressors of the officiating role (Rice et al., 2016) and ultimately led to increased levels of anxiety (Martín-Merino et al., 2010), stress (Rainey \& Hardy, 1995; Voight, 2009), fear, and decreased self-esteem. More specifically, 
the focus on gender presentation and the female body was also expressed. The participants detailed being held to unrealistic physical expectations based on antiquated perceptions of gender, including the need to pursue a specific body shape and present with feminine attributes. Such expectations led to discomfort and, in some instances, body image issues. Because negative body image perceptions have been closely linked to lowered emotional regulation skills (Shriver et al., 2016), low self-esteem (Davidson \& McCabe, 2006), and other negative indicators of mental health (Mercurio \& Landry, 2008), this finding highlights the need for sport managers to push against the current narrative and promote mental health wellness.

Further, systemic macroaggressions, such as utilizing the 'old boys' network' as a means for structural decision making, created an environment inherently built to keep women out. This may help explain why women athletes are nearly twice as likely to experience mental health challenges (Breslin et al., 2019; Gorczynski et al., 2017), and why Gendered Aggressions were so salient for the female referee participants. Such 'everyday' forms of sexism are particularly concerning as they have been related to negative health outcomes including anxiety, depression, and psychological distress (Gouttebarge et al 2017; Moradi \& Subich, 2002). These findings aligned with previous research (Webb et al, 2021) which revealed that gendered abuse and male dominated sporting cultures negatively impacted referee mental health. Attempting to operate in an environment that continuously reinforces the idea that you do not belong (Burton, 2015) or that you are part of the out-group (Jacobs et al., 2020) may have significant implications regarding one's mental health (Webb et al., in press). Thus, the Gendered Aggressions found in this study clearly impacted female officials and their mental health.

For female officials in this study, mental health was generally ignored or obfuscated by the associated Stigma and lack of Resources and Support. It is interesting to note that 15 of the 
20 participants indicated that mental health is rarely discussed in society, even outside of officiating. Despite more awareness to the subject brought by athletes like Naomi Osaka and Abby Wambach, the fact that $75 \%$ of respondents indicated mental health is rarely discussed in their circles might be an indication about the dearth of discussions about mental health in the broader culture. Gluck (2019) defined stigma as perceived negative attributes that causes someone to devalue the whole person and is often associated with discrimination and fear. Referees, like athletes, are limited in their ability to address such concerns for fear of losing assignments or being perceived as mentally weak (Bauman, 2016). The stigmatization of mental health issues and the fear of reprisal within the officiating context points to a "lack of administrative concern" for the individuals within the system (Tingle et al., 2014; Warner et al., 2013). Instead of facilitating open dialogue about mental health, administrators are seen to promote the expectation that one must officiate through the pain. This led to the perception that administrators considered referees prepared to work if they were physically fit, with no regard to mental fitness. Such a system exacerbates the need to hide mental health issues, which formalizes a mental health system based on the ability to perform rather than diagnostic criteria (Coyle et al., 2017) and all but guarantees the under-reporting of mental health problems (Schwenk, 2000). In describing a system that normalizes the stigmatization of mental health issues, officials in this study noted a significant need to create a culture which fosters open, honest dialogue regarding mental health. This notion is supported by numerous entities which have begun to prioritize the mental health of their sport stakeholders (i.e., athletes and coaches) (Webb, 2020) and challenges referee associations to make similar strides in promoting holistic wellness for their constituents. Given that $80 \%$ of officials leave within their first three years 
(Stump 2018), and that there is a general shortage of female officials the need to address these concerns is paramount.

Beyond the systemic stigmatization of mental health issues, the results also revealed that there are few mental health resources available (i.e., Resources and Support) for officials in general and to female officials in particular, which aligns with the findings of Webb et al. (in press). Several of the referees in this study revealed that they sometimes experienced common mental health conditions such as distress, anxiety, and depression, yet none reported access to mental health education, training, or a support structure that emphasized mental well-being. Coupled with a myriad of studies that report the lack of available education and mentoring (Ridinger, 2015; Ridinger, Kim, et al., 2017; Ridinger, Warner, et al., 2017; Warner et al., 2013) this was not surprising. Addressing this oversight should be prioritized by sport managers. The participants suggested one way to enhance Resources and Support was to embed mental health training in camps, conferences, and association meetings. This finding is consistent with and extends literature on continuing education as integral to the retention and success of referees (Ridinger, Kim, et al., 2017; Ridinger, Warner, et al., 2017). Further, the need for formalized mentorship structures was detailed. The officials noted the value of intentionally selecting mentor/mentee partnerships and considering gender dynamics in these selections to allow for candid discussion about topics such as mental health. Similar to conclusions of Gouttebarge and colleagues (2017), the lack of available mental health Resources and Support illuminates the glaring need for educating, training, and supporting officials on matters of mental health.

While the female basketball officials in this study often associated mental health with mental illness, they also highlighted officiating as a strategy for coping with stress (i.e., Catharsis); thereby positioning officiating as a role that may support positive mental health 
outcomes, given the elimination or management of structural and organizational dissatisfiers. In many instances, participating as a referee was a positive outlet allowing individuals to let go of daily stressors and practice personal anxiety management (Woodward, 2004). This aligns with the World Health Organization's (2014) definition, which connects physical and mental wellbeing. It also connects with Warner (2019) who advocated for sport as medicine and with Boone and Leadbeater (2006) who found that sport can buffer depressive symptoms. When participants were able to officiate, unbound from the constraints of structural inequities, they described finding power on the court. Such empowerment may lead to positive mental health outcomes as suggested by Lubans et al. (2016) who found that sport can enhance self-perception. Officiating as a Catharsis is a key finding of this study as it highlights the potential for the role to provide positive mental health outcomes for the individual and expands the value of the role beyond the provision of service to others.

\section{Implications and Future Research}

This study extends previous research on sports officials (Kellett \& Shilbury, 2007; Nordstrom et al., 2016; Ridinger, 2015; Schaeperkoetter, 2017; Tingle et al., 2014; Warner et al., 2013) and the findings point to numerous practical implications and opportunities for future research. Though participant recruitment for this study intentionally included female referees working multiple levels of the game and representing the geographic diversity of the United States, it is important to note that 20 referees participated in the study. While these findings should not be generalized beyond this sample, rich data and detailed data collection methods allow readers to compare these findings to other situations. As Shenton (2004) concluded this, "allow readers to have a proper understanding of it [the data], thereby enabling them to compare the instances of the phenomenon described in the research report with those that they have seen 
emerge in their situations" (p. 70). Additionally, the study represents an important first step in understanding how female sports officials experience and construct mental health. Specifically, as detailed by our participants, summer camps, regularly scheduled association meetings, and continuing education sessions are all opportunities for developmental programs which focus on addressing mental health concerns. Primarily the recruitment and retention of referees starts with inclusion efforts and the reduction of Gendered Aggressions; it continues with intentional steps taken to reduce Stigma associated with mental health and the provision of adequate Resources and Support.

Another way to impact retention is to increase mental health literacy (Webb et al., in press) for all participants. As administrators develop resources to improve mental health for athletes, coaches, and parents, sport governing bodies should consider referees as an important stakeholder and involve them in conversations about mental health. In coordination with sport organizations, officiating associations need to reduce the Stigma around mental health and mental illness, which prevents referees from reporting concerns about anxiety, depression, or stress. They also need to proactively share Resources and Support to increase mental health literacy (Webb et al., in press) for referees and match officials. Finally, building on the findings that officiating is a Catharsis, marketing and recruiting campaigns should highlight the positive benefits of officiating. Further, detailing the cathartic elements of officiating could be utilized in training and education programs to encourage referees to consider reframing the experience as a stress reliever rather than stress inducer. When combined with increasing mental health resources, and changing officiating culture to reduce gendered aggressions, this reframing could likely enhance retention. Similar to the work of Kellett and Shilbury, (2007) which demonstrated that the reframing of abuse for officials improved retention, promoting officiating as a Catharsis, 
while simultaneously reducing the negative factors described by our participants could have a similar outcome.

This study highlights why it is important to study sports officials as heterogeneous groups (Tingle et al., 2014), rather than a collective. Similar to other areas of sport, female officials have unique workplace experiences and experience officiating differently than their male counterparts. Specifically, the experience of Gendered Aggressions needs to be better understood to improve retention and recruitment efforts. Also, Catharsis warrants further attention; understanding how officiating, a role rife with stress, can be a positive outlet that allows individuals to escape from daily stressors was a noteworthy finding. Additional future research should expand the sample, which could be accomplished by interviewing participants from other sports in the United States with large numbers of female referees (e.g., field hockey, lacrosse, softball). Alternatively, a cross-cultural study exploring differences and similarities in how female referees experience mental health in different countries would broaden our understanding of the phenomenon. Scholars could also conduct future research on developing a Referee Mental Health Scale to explore relationships between wellness variables (e.g., exercise, sleep, sense of community, and optimism) and levels of depressive symptoms, anxiety, stress, and self-reported mental health. Developing a better understanding of the coping mechanisms of female referees who have been retained will be an important step in the process to develop systems to enhance recruitment efforts, develop mentorship programs, and create continuing education aimed at enhancing mental health literacy for referees.

\section{Conclusion}

This study was the first in the United States to examine the experience and construction of mental health among female sports officials. The most compelling result of this study was the 
contradictory nature of officiating for women. Officiating can be both a source of stress as well as an outlet to relieve stress. The findings revealed that the female basketball officials in this study experience mental health as a construct shrouded by gendered aggressions and stigma. As a result, mental health was seen to be overlooked by administrators and the necessary resources to appropriately address and manage mental health were found to be non-existent. This created a complex setting for female officials as sport is rife with gender disparities that may exacerbate the potential for mental health concerns. Despite these challenges, officiating was perceived as a cathartic experience for female basketball referees, contributing positively to their mental health. It is important for sport organizations to understand the dichotomy of officiating and to manage both sides. Officiating associations need to highlight the cathartic aspects of officiating that can contribute to positive mental health while also providing resources to address and support mental health concerns. By managing both sides, the stigma associated with mental health can be reduced and the officiating culture can be changed to be more inclusive for female officials. 


\section{References}

Allen-Collinson, J. (2009). Sporting embodiment: sports studies and the (continuing) promise of phenomenology. Qualitative Research in Sport and Exercise, 1, 279-296. https://doi.org/10.1080/19398440903192340

Anshel, M. H., \& Weinberg, R. S. (1995). Sources of acute stress in American and Australian basketball referees. Journal of Applied Sport Psychology, 7(1), 11-22. https://doi.org/10.1080/10413209508406297

Anshel, M. H., \& Wells, B. (2000a). Personal and situational variables that describe coping with acute stress in competitive sport, The Journal of Social Psychology, 140, 434-450. https://doi.org/10.1080/00224540009600483

Anshel, M. H., \& Wells, B. (2000b). Sources of acute stress and coping styles in competitive sport. Anxiety, Stress \& Coping, 13, 1-26. https://doi.org/10.1080/10615800008248331

Anshel, M. H., Sutarso, T., Ekmekci, R., \& Saraswati, I. W. (2014). A model linking sources of stress to approach and avoidance coping styles of Turkish basketball referees. Journal of Sports Sciences, 32(2), 116-128. https://doi.org/10.1080/02640414.2013.816762

Bauman, N. J. (2016). The stigma of mental health in athletes: Are mental toughness and mental health seen as contradictory in elite sport? British Journal of Sports Medicine, 50, 135 136. http://doi.org/10.1136/bjsports-2015-095570

Breger, M. L., Holman, M. J., \& Guerrero, M. D. (2019). Re-Norming sport for inclusivity: How the sport community has the potential to change a toxic culture of harassment and abuse. Journal of Clinical Sport Psychology, 13(2), 274-289. https://doi.org/10.1123/jcsp.2019$\underline{0004}$ 
Boone, E. M., \& Leadbeater, B. J. (2006). Game on: Diminishing risks for depressive symptoms in early adolescence through positive involvement in team sports. Journal of Research on Adolescence, 16, 79-90. https://doi.org/10.1111/j.1532-7795.2006.00122.x

Borel-Hänni, F. (2015). Information through a lens: Media and journalists' social responsibility towards French football referees. European Journal for Sport and Society, 12, 397-419. https://doi.org/10.1080/16138171.2015.11730365

Braun, V., \& Clarke, V. (2006). Using thematic analysis in psychology. Qualitative Research in Psychology, 3(2), 77-101. https://doi.org/10.1191/1478088706qp063oa

Breslin, G., Shannon, S., Ferguson, K., Devlin, S., Haughey, T., \& Prentice, G. (2019). Predicting athlete mental health stigma using the theory of reasoned action framework. Journal of Clinical Sport Psychology, 13(1), 103-115. https://doi.org/10.1123/jcsp.2017$\underline{0055}$

Burla, L., Knierim, B., Barth, J., Liewald, K., Duetz, M., \& Abel, T. (2008). From text to codings: intercoder reliability assessment in qualitative content analysis. Nursing research, 57(2), 113-117.

Burton, L. J. (2015). Underrepresentation of women in sport leadership: A review of research, Sport Management Review, 18, 155-165. https://doi.org/10.1016/j.smr.2014.02.004

Carr, C., \& Davidson, J. (2014, October). The psychologist perspective. In G. T. Brown (Ed.) Mind, body, and sport: Understanding and supporting student-athlete mental wellness (pp. 17-20). National Collegiate Athletic Association.

Cavanagh, A., Wilson, C. J., Kavanagh, D. J., \& Caputi, P. (2015). Differences in the expression of symptoms in men versus women with depression: A systematic review and meta- 
analysis. Harvard Review of Psychiatry, 25, 29-38. https://doi.org/10.1097/HRP.0000000000000128

Corbin, J., \& Strauss, A. L. (2008). Basics of qualitative research: Techniques and procedures for developing grounded theory. California (Estatu Batuak): Sage.

Coutts, A. J., \& Raeburn, P. R. J. (2000). Time and motion analysis of the AFL field umpire. Journal of Science and Medicine in Sport, 3(2), 132-139. https://doi.org/10.1016/S1440-

\section{$\underline{2440(00) 80075-4}$}

Coyle, M., Gorczynski, P., \& Gibson, K. (2017). "You have to be mental to jump off a board any way": Elite divers' conceptualizations and perceptions of mental health. Psychology of Sport and Exercise, 29, 10-18. https://doi.org/10.1016/j.psychsport.2016.11.005

Cuskelly, G., \& Hoye, R. (2013). Sports officials' intention to continue. Sport Management Review, 16, 451-464. https://doi.org/10.1016/j.smr.2013.01.003

Davidson, T. E., \& McCabe, M. P. (2006). Adolescent body image and psychosocial functioning. The Journal of Social Psychology, 146, 15-30. https://doi.org/10.3200/SOCP.146.1.15-30

Dell, C., Gervis, M., \& Rhind, D. (2016). Factors influencing soccer referee's intentions to quit the game. Soccer \& Society, 17, 109-119. https://doi.org/10.1080/14660970.2014.919275

Eilerson, N. (2017, Jun 16). Verbal abuse from parents, coaches is causing referee shortage in youth sports. The Washington Post. https://www.washingtonpost.com/sports/highschools/verbal-abuse-from-parents-coachesis-causing-a-referee-shortage-in-youth-and-high-school-sports/2017/06/16/cf02a016499a-11e7-a186-60c031eab644_story.html 
Elo, S., Kääriäinen, M., Kanste, O., Pölkki, T., Utriainen, K., \& Kyngäs, H. (2014). Qualitative content analysis: A focus on trustworthiness. SAGE open, 4(1), 1-10. https://doi.org/10.1177/2158244014522633.

File, K. A. (2017). 'I didn’t know you were allowed two goalkeepers': How football managers negotiate invitations to criticise referees in the media. In D. Caldwell, J. Walsh, E. W. Vine, \& J. Jureidini (Eds.) The discourse of sport: Analyses from social linguistics (pp. 71-91). Routledge.

Folkesson, P., Nyberg, C., Archer, T., \& Norlander, T. (2002). Soccer referees' experience of threat and aggression: Effects of age, experience, and life orientation on outcome of coping strategy. Aggressive Behavior, 28, 317-327. https://doi.org/10.1002/ab.90028

Gerbing, K. K., \& Thiel, A. (2016). Handling of medical knowledge in sport: Athletes' medical opinions, information seeking behaviours and knowledge sources. European Journal of Sport Science, 16, 141-148. https://doi.org/10.1080/17461391.2014.989278

Gluck, S. (2019, October 23) What is stigma? HealthPlace. https://www.healthyplace.com/stigma/stand-up-for-mental-health/what-is-stigma Gorczynski, P., Sims-Schouten, W., Hill, D., \& Wilson, J. C. (2017). Examining mental health literacy, help seeking behaviours, and mental health outcomes in UK university students. The Journal of Mental Health Training, Education and Practice, 12, 111-120. https://doi.org/10.1108/JMHTEP-05-2016-0027

Gouttebarge, V., Johnson, U., Rochcongar, P., Rosier, P., \& Kerkhoffs, G. (2017). Symptoms of common mental disorders among professional football referees: A one-season prospective study across Europe. The Physician and SportsMedicine, 45(1), 1, 11-16. http://dx.doi.org/10.1080/00913847.2017.1248796 
Guest, G., Bunce, A., \& Johnson, L. (2006). How many interviews are enough? An experiment with data saturation and variability. Field Methods, 18, 59-82. https://doi.org/10.1177/1525822X05279903

Gulliver, A., Griffiths, K. M., Christensen, H., Mackinnon, A., Calear, A. L., Parsons, A., Bennett, K., Batterham, P. J., \& Stanimirovic, R. (2012). Internet-based interventions to promote mental health help-seeking in elite athletes: An exploratory randomized controlled trial. Journal of Medical Internet Research, 14(3), e69. https://doi.org/10.2196/jmir.1864

Guzel, P. (2020). Perceptions and experiences of world karate referees: Implications for gender (in)equality. African Educational Research Journal, 8, 618-626. https://doi.org/10.30918/AERJ.83.20.136

Hancock, D. J., Bennett, S., Roaten, H., Chapman, K., \& Stanley, C. (2020). An analysis of literature on sport officiating research. Research Quarterly for Exercise and Sport, Advance online publication. https://doi.org/10.1080/02701367.2020.1756198

Hughes, L., \& Leavey, G. (2012). Setting the bar: Athletes and vulnerability to mental illness. British Journal of Psychiatry, 200(2), 95-96.

Hanton, S., Fletcher, D., \& Coughlan, G. (2005). Stress in elite sport performers: A comparative study of competitive and organizational stressors, Journal of Sports Sciences, 23, 11291141. https://doi.org/10.1080/02640410500131480

Hindman, L. C., \& Walker, N. A. (2020). Sexism in professional sports: How women managers experience and survive sport organizational culture. Journal of Sport Management, 34, 64-76. https://doi.org/10.1123/jsm.2018-0331 
Huang, Y. P., Kellett, U. M., St John, W., \& Lee, S. (2006). Analysis phenomenology and application to nursing research. Hu li za zhi The Journal of Nursing, 53(2), 49-58.

Jacobs, B. L., Zvosec, C. C., \& Oja, B. D. (2019). Navigating Role Ambiguity \& Conflict: Exploring the Role of the Referee Within the Olympic Sporting Structure. Journal of Amateur Sport, 5(2), 115-137.

Jacobs, B., Tingle, J. K., Oja, B., \& Smith, M. (2020). Exploring referee abuse through the lens of the collegiate rugby coach. Sport Management Review, 23, 39-51. https://doi.org/10.1016/j.smr.2019.03.004

Jewett, R., Sabiston, C. M., Brunet, J., O'Loughlin, E. K., Scarapicchia, T., \& O'Loughlin, J. (2014). School sport participation during adolescence and mental health in early adulthood. Journal of Adolescent Health, 55, 640-644. https://doi.org/10.1016/j.jadohealth.2014.04.018

Johansen, B. T., \& Haugen, T. (2013). Anxiety level and decision-making among Norwegian top-class soccer referees. International Journal of Sport and Exercise Psychology, 11, 215-226. https://doi.org/10.1080/1612197X.2013.773665

Jordan, P., Upright, P., \& Forsythe, S. (2019). Rural Kentucky sport officials' perspectives on recruitment, training and retention. KAHPERD Journal, 56, 59-72.

Kaier, E., Cromer, L. D., Johnson, M. D., Strunk, K., \& Davis, J. L. (2015). Perceptions of mental illness stigma: Comparisons of athletes to nonathlete peers. Journal of College Student Development, 56, 735-739. http://doi.org/10.1353/csd.2015.0079

Kaissidis-Rodafinos, A., Anshel, M. H., \& Porter, A. (1997). Personal and situational factors that predict coping strategies for acute stress among basketball referees, Journal of Sports Sciences, 15, 427-436. https://doi.org/10.1080/026404197367218 
Kellett, P., \& Shilbury, D. (2007). Umpire participation: Is abuse really the issue? Sport Management Review, 10, 209-229. https://doi.org/10.1016/S1441-3523(07)70012-8

Kellett, P., \& Warner, S. (2011). Creating communities that lead to retention: The social worlds and communities of umpires. European Sport Management Quarterly, 11, 471-494. https://doi.org/10.1080/16184742.2011.624109

Krane, V. (2015). Gender nonconformity, sex variation, and sport. In R. J. Schinke \& K. R. McGannon (Eds.), The psychology of sub-culture in sport and physical activity, (pp.4863). Routledge.

Kubayi, A., Toriola, A., \& Didymus, F. (2018). Development and initial validation of an instrument to assess stressors among South African sports coaches. Journal of Sports Sciences, 36, 1378-1384.https://doi.org/10.1080/02640414.2017.1385264

Lambert, V. A., Lambert, C. E., \& Ito, M. (2004). Workplace stressors, ways of coping and demographic characteristics as predictors of physical and mental health of Japanese hospital nurses. International Journal of Nursing Studies, 41, 85-97. https://doi.org/10.1016/S0020-7489(03)00080-4

Laverty, S. M. (2003). Hermeneutic phenomenology and phenomenology: A comparison of historical and methodological considerations. International Journal of Qualitative Methods, 2, 21-35. https://doi.org/10.1177/160940690300200303

Leicht, A. S. (2008). Physiological demands of basketball referring during international competition. Journal of Science and Medicine in Sport, 11(3), 357-360. https://doi.org/10.1016/j.jsams.2007.05.006

Lincoln, Y. S., \& Guba, E. G. (1985). Naturalistic inquiry. Sage. 
Livingston, L. A., Forbes, S. L., Wattie, N., Pearson, N., Camacho, T., \& Varian, P. (2017). Sport officiating recruitment, development, and retention: A call to action. Current Issues in Sport Science, 2, 1-9. https://doi.org/10.15203/CISS_2017.011

Lopez, R. L., \& Levy, J. J. (2013). Student athletes' perceived barriers to and preferences for seeking counseling. Journal of College Counseling, 16(1), 19-31. https://doi.org/10.1002/j.2161-1882.2013.00024.x

Lubans, D., Richards, J., Hillman, C., Faulkner, G., Beauchamp, M., Nilsson, M., Kelly, P., Smith, J., Raine, L., \& Biddle, S. (2016). Physical activity for cognitive and mental health in youth: A systematic review of mechanisms. Pediatrics, 138, e20161642. https://doi.org/10.1542/peds.2016-1642

Madrigal, L., \& Robbins, J. E. (2020). Student-athlete stress: An examination in United States collegiate athletics. Journal for the Study of Sports and Athletes in Education, 14, 123 139. https://doi.org/10.1080/19357397.2020.1774261

Martín-Merino, E., Ruigómez, A., Wallander, M. A., Johansson, S., \& García-Rodríguez, L. A. (2010). Prevalence, incidence, morbidity and treatment patterns in a cohort of patients diagnosed with anxiety in UK primary care. Family Practice, 27, 9-16. https://doi.org/10.1093/fampra/cmp071

Melton, E. N., \& Bryant, M. J. (2017). Intersectionality: The impact of negotiating multiple identities for women in sport leadership. In L. J. Burton \& S. Leberman (Eds.), Women in sport leadership: Research and practice for change (pp. 62-82). Routledge. https://doi.org/10.4324/9781315542775 
Mercurio, A. E., \& Landry, L. J. (2008). Self-objectification and well-being: The impact of selfobjectification on women's overall sense of self-worth and life satisfaction. Sex Roles, 58, 458-466. https://doi.org/10.1007/s11199-007-9357-3

Mellick, M. (2020). Soccer referee mental health: Developing a network of soccer referee mental health champions. In J. G. Dixon, J. B. Barker, R. C. Thelwell, \& I. Mitchell (Eds.) The psychology of soccer (pp. 278-291). Routledge.

Merriam, S. B., \& Tisdell, E. J. (2016). Designing your study and selecting a sample. Qualitative research: A guide to design and implementation. Jossey-Bass.

Misener, K., \& Doherty, A. (2009). A case study of organizational capacity in nonprofit community sport. Journal of Sport Management, 23, 457-482. https://doi.org/10.1123/jsm.23.4.457

Moradi, B., \& Subich, L. M. (2002). Perceived sexist events and feminist identity development attitudes: Links to women's psychological distress. The Counseling Psychologist, 30(1), 44-65.

Moustakas, C. (1994). Phenomenological research methods. Sage publications.

Nordstrom, H., Warner, S., \& Barnes, J. (2016). Behind the stripes: Female football officials' experiences. International Journal of Sport Management and Marketing, 16, 259-279. https://doi.org/10.1504/IJSMM.2016.077934

Onwuegbuzie, A. J., \& Leech, N. L. (2007). Validity and qualitative research: An oxymoron? Quality \& Quantity: International Journal of Methodology, 41(2), 233-249. https://doi.org/10.1007/s11135-006-9000-3

Phillips, P., \& Fairley, S. (2014). Umpiring: A serious leisure choice. Journal of Leisure Research, 46, 184-202. https://doi.org/10.1080/00222216.2014.11950319 
Pinto, B. (2019, July 18). How NBA players are taking the lead on mental health. Insight. https://www.thechicagoschool.edu/insight/psychology/nba-mental-healthawareness/\#: : :text=In\%202018\%20the\%20National\%20Basketball,emphasis\%20on \%20 $\underline{\text { mental } \% 20 \text { health } \% 20 \text { education }}$

Polit, D. F., Beck, C. T. (2012). Nursing research: Principles and methods. Lippincott Williams \& Wilkins.

Putukian, M. (2016). The psychological response to injury in student athletes: A narrative review with a focus on mental health. British Journal of Sports Medicine, 50, 145-148. https://doi.org/10.1136/bjsports-2015-095586

Pyett, P. M. (2003). Validation of qualitative research in the "real world." Qualitative Health Research, 13, 1170-1179.

Rainey, D. W. (1995). Stress, burnout, and intention to terminate among umpires. Journal of Sport Behaviour, 18, 312-323.

Rainey, D. W., \& Hardy, L. (1999). Sources of stress, burnout and intention to terminate among rugby union referees, Journal of Sports Sciences, 17, 797-806. https://doi.org/10.1080/026404199365515

Rao, A. L., \& Hong, E. S. (2016). Understanding depression and suicide in college athletes: Emerging concepts and future directions. British Journal of Sports Medicine, 50, 136137. https://doi.org/10.1136/bjsports-2015-095658

Rao, J. V., \& Chandraiah, K. (2011). Occupational stress, mental health and coping among information technology professionals. Indian Journal of Occupational and Environmental Medicine, 15, 22-26. https://doi.org/10.4103/0019-5278.99686 
Reardon, C. L., Hainline, B., Aron, C. M., Baron, D., Baum, A. L., Bindra, A., . . . \& Derevensky, J. L. (2019). Mental health in elite athletes: International Olympic Committee consensus statement (2019). British Journal of Sports Medicine, 53(11), 667699.

Rice, S. M., Purcell, R., De Silva, S., Mawren, D., McGorry, P. D., \& Parker, A. G. (2016). The mental health of elite athletes: A narrative systematic review. Sports Medicine, 46, 13331353. https://doi.org/10.1007/s40279-016-0492-2

Ridinger, L. L. (2015). Contributors and constraints to involvement with youth sports officiating. Journal of Amateur Sport, 1, 103-127. https://doi.org/10.17161/jas.v1i2.4946

Ridinger, L. L., Kim, K. R., Warner, S., \& Tingle, J. K. (2017). Development of the referee retention scale. Journal of Sport Management, 31, 514-527. https://doi.org/10.1123/jsm.2017-0065

Ridinger, L. L., Warner, S., Tingle, J. K., \& Kim, K. R. (2017). Why referees stay in the game. Global Sport Business Journal, 5(3), 22-37.

Ruddock-Hudson, M., Ruddock, S., \& Rahimi-Golkhandan, S. (2019). Blowing the whistle on mental health and wellbeing: The experiences of Australian Football League Umpires. Journal of Science and Medicine in Sport, 22(S2), S105. https://doi.org/10.1016/j.jsams.2019.08.140

Schaeperkoetter, C. (2017). Basketball officiating as a gendered arena: An autoethnography. Sport Management Review, 20, 128-141. https://doi.org/10.1016/j.smr.2016.05.001

Schinke, R. J., Stambulova, N. B., Si, G., \& Moore, Z. (2018). International society of sport psychology position stand: Athletes' mental health, performance, and development. 
International Journal of Sport and Exercise Psychology, 16, 622-639. https://doi.org/10.1080/1612197X.2017.1295557

Schreier, M. (2012). Qualitative content analysis in practice. Sage publications.

Schwenk, T. L. (2000). The stigmatization and denial of mental illness in athletes. British Journal of Sports Medicine. 34(1), 4-5. https://doi.org/10.1136/bjsm.34.1.4

Shenton, A. K. (2004). Strategies for ensuring trustworthiness in qualitative research projects. Education for Information, 22(2), 63-75. https://doi.org/10.3233/EFI-2004-22201

Shriver, L. H., Wollenberg, G., \& Gates, G. E. (2016). Prevalence of disordered eating and its association with emotion regulation in female college athletes. International Journal of Sport Nutrition \& Exercise Metabolism, 26, 240-248.

https://doi.org/10.1123/ijsnem.2015-0166

Stump, S. (2018, March 29). Youth sports referees across the US are quitting because of abusive parents. Today. https://www.today.com/parents/youth-sports-referees-across-us-arequitting-because-abusive-parents-t126087

Taylor, A. H., Daniel, J. V., Leith, L., \& Burke, R. J. (1990). Perceived stress, psychological burnout and paths to turnover intentions among sport officials. Journal of Applied Sport Psychology, 2, 84-97. https://doi.org/10.1080/10413209008406422

Tingle, J. K. (2020). Instant replay in the National Basketball Association. In M. Armenteros, A. Benitez, \& M. A. Betancor (Eds.). The use of video technologies in refereeing football and other sports (pp. 119-137). Routledge. https://doi.org/10.4324/9780429455551

Thomas, E., \& Magilvy, J. K. (2011). Qualitative rigor or research validity in qualitative research. Journal for specialists in pediatric nursing. 16, 151-155. 
Tingle, J. K., Warner, S., \& Sartore-Baldwin, M. L. (2014). The experience of former women officials and the impact on the sporting community. Sex Roles, 71, 7-20. https://doi.org/10.1007/s11199-014-0366-8

U.S. Department of Health and Human Services. (2019). The National Youth Sports Strategy. https://health.gov/sites/default/files/2019-10/National_Youth_Sports_Strategy.pdf.

Van Raalte, J. L., Brewer, B. W., Brewer, D. D., \& Linder, D. E. (1992). NCAA Division II college football players' perceptions of an athlete who consults a sport psychologist. Journal of Sport and Exercise Psychology, 14, 273-282. https://doi.org/10.1123/jsep.14.3.273

Voight, M. (2009). Sources of stress and coping strategies of US soccer officials. Stress and Health, 25, 91-101. https://doi.org/10.1002/smi.1231

Walker, N. A., \& Melton, E. N. (2015). The triple threat: Examining the intersection of gender, race, and sexual orientation in sport organizations. Journal of Sport Management, 29, 257-271. https://doi.org/10.1123/jsm.2013-0079

Warner, S. (2019). Sport as medicine: How F3 is building healthier men and communities. Sport Management Review, 22, 38-52. https://doi.org/10.1016/j.smr.2018.06.006

Warner, S., Tingle, J. K., \& Kellett, P. (2013). Officiating attrition: Considering the experiences of referees from a sport development perspective. Journal of Sport Management, 27(4), 316-328. https://doi.org/10.1123/jsm.27.4.316

Webb, T. (2018). Referees and the media: A difficult relationship but an unavoidable necessity. Soccer and Society, 19, 205-221. https://doi.org/10.1080/14660970.2015.1133414 
Webb, T. (2020). The future of officiating: Analysing the impact of COVID-19 on referees in world football, Soccer \& Society, (22), 12-18. https://doi.org/10.1080/14660970.2020.1768634

Webb, T., \& Hill, D. (2020). The psychology of soccer referees. In J. G. Dixon, J. B. Barker, R. C. Thelwell, \& I. Mitchell (Eds.) The psychology of soccer (pp. 74-87). Routledge.

Webb, T., Cleland, J., \& O'Gorman, J. (2017). The distribution of power through a media campaign: The respect program, referees, and abuse in Association Football. Journal of Global Sport Management, 2(3), 162-181. https://doi.org/10.1080/24704067.2017.1350591

Webb, T., Gorczynski, P., Oftadeh-Moghadam, S., \& Grubb, L. (2021). Experience and construction of mental health among English female match officials. The Sport Psychologist, 35, 1-10. https://doi.org/10.1123/tsp.2020-0086

Webb, T., Dicks, M., Thelwell, R., van der Kamp, J., \& Rix-Lievre, G. (2020). An analysis of soccer referee experiences in France and the Netherlands: Abuse, conflict, and level of support. Sport Management Review, 23, 52-65. https://doi.org/10.1016/j.smr.2019.03.003

Willig, C. (2007). Reflections on the use of a phenomenological method. Qualitative Research in Psychology, 4, 209-225. https://doi.org/10.1080/14780880701473425

Wolanin, A., Hong, E., Marks, D., Panchoo, K., \& Gross, M. (2016). Prevalence of clinically elevated depressive symptoms in college athletes and differences by gender and sport. British Journal of Sports Medicine, 50, 167-171. https://doi.org/10.1136/bjsports-2015$\underline{095756}$

Woodward, K. (2004). Rumbles in the jungle: Boxing, racialization and the performance of masculinity. Leisure Studies, 23, 5-17. https://doi.org/10.1080/0261436042000182281 
World Health Organization. (2004). Promoting mental health: concepts, emerging evidence, practice (Summary Report) Geneva: World Health Organization.

Yang, J., Peek-Asa, C., Corlette, J. D., Cheng, G., Foster, D. T., \& Albright, J. (2007).

Prevalence of and risk factors associated with symptoms of depression in competitive collegiate student athletes. Clinical Journal of Sport Medicine, 17, 481-487.

https://doi.org/10.1097/JSM.0b013e31815aed6b 